\title{
HISTORY OF SCIENCE
}

DOI: 10.46340/ephd.2021.7.2.5

\author{
Bohdana Manchul \\ ORCID ID: https://orcid.org/0000-0002-6937-1403 \\ Yuriy Fedkovych Chernivtsi National University, Ukraine \\ DISCIPLINARY KNOWLEDGE: HISTORY, \\ EVOLUTION, AND CONTEMPORARY \\ SCIENTIFIC STATUS
}

The article is devoted to the analysis of the formation and historical evolution of the disciplinary science. In particular, several key points were emphasized. First, to understand the structure of modern science, it was necessary to consider different approaches to the emergence of disciplinary knowledge including the emergence of certain disciplines in different historical epochs. In the Ancient period for the first time, there was a division of knowledge into fields; in the Middle Ages - the first European universities were found, they were characterized by the professionalization of knowledge; in the Renaissance time fundamental branches of science were developed; the Enlightenment focused on the codification of knowledge and establishment of research methods; in the 19th century - the humanities became a part of science; and in the 20th century poly-, trans- and interdisciplinary research weakened rigorous disciplinary boundaries. Secondly, an important place in understanding the essence of academic disciplines belongs to criteria in which they differ from one another. If in antiquity such criteria were based on objects and methods of investigation, which determined a certain scientific field, then contemporary disciplinary science also takes into account the social, psychological, paradigmatic components. Third, the study of the internal structure of the discipline shows that each scientific field consists of object, methodological, linguistic, and value components. And fourth, in modern disciplinary discourse, there are discussions about the effectiveness of this method of acquiring new knowledge. For centuries the disciplinary approach in science was considered one that led to true knowledge. However, in the late 20th century disciplinarity was seen as outdated and in need of rethinking in the interdisciplinary way. However, in the early 21 st century it was considered to be dynamic and flexible. Since more subject areas are emerging, scientific disciplines are characterized more by the methodology they apply to certain topics or research areas, rather than through the topics or areas of research themselves.

Keywords: science, academic discipline, scientific method, interdisciplinarity, classification, research area.

Articulation of the issue. During its long development, science has gone through many stages of transformation. This transformation concerned scientific approaches, methods, structure, language, etc. In the last 150 years, there has been a significant spread of disciplinary knowledge, which has affected how science is done and how the learning process takes place. The development of disciplinary specialization has caused concern and debate over the decline of standards of intellectual excellence. At the same time, integrative processes inside science have become one of the stages of disciplinary transformation.

Current scientific researches and issues analysis. The concept of justice has been studied in numerous works, among them there should be mentioned those by A. Abbot, A. Anderson, J. Valente, A. Appaduri, M. Boisot, E. Cohen, S. Lloyd. It is worth mentioning M. Foucault's interpretation of concept of discipline, R. Newman's idea of specialized knowledge, D. Schumway's and E. Messer-Davidov's explanation of separation of the humanities from science, T. Becher's and P. Trowler's theory of academic tribes and territories, A. Krishnan's observations on disciplinarity versus interdisciplinarity, J. Klein's and J. Moran's analysis of the rise of interdisciplinarity. 
Unresolved problem analysis. The formation of modern scientific disciplines in the late 19th century was accompanied by discussions about what the intellectual map of that time should look like. In the mid20th century, these discussions moved towards rethinking of a discipline per se. These trends have been linked to several factors. Firstly, it is the rapid spread of education, which required a new approach to the systematization and presentation of knowledge. Secondly, the critique of the scientific status of the humanities. Thus, in the socio-humanitarian environment, there is a belief that disciplinary boundaries based on the objects of research and specialized procedures are a form of scientific positivism which does not take into account the diversity of human and social activities. These questions are still being debated and there is a need for studying the role of disciplinarity in terms of its history, transformation and contemporary scientific status in order to understand other ways of conducting a scientific research, i.e., transdisciplinarity, interdisciplinarity, polydisciplinarity, etc.

Research objectives setting. The investigation is aimed at studying the history of disciplinarity from ancient to modern times, focusing on research criteria and inquiry approaches. Particular attention is paid to the evolution of the key components of disciplinarity.

The methodological basis of research lies within hypothetico-deductive method, historic and systemic approaches to understanding the dynamics of disciplinarity. The methods of analysis, synthesis, and generalization were also used.

Research results presentation. Scientific disciplines are divided and function according to generally accepted criteria. In particular, all academic disciplines have a set of relevant terms, theories, a special way of studying objects. Each discipline has a particular set of methods and techniques for conducting research and verifying its results. Disciplines are also characterized by a special form of communication through publications, reviews, conferences, professional associations, etc. There is also a clear pattern in the training of specialists in a particular field.

Scientific disciplines are abstractions. Their essence is determined by socio-cognitive, institutional, and technological parameters. Today, slogans such as "disciplinary science is useless" are quite common. Acceleration of scientific and technological development, globalization of knowledge, hybridization of cultures, new communication technologies have contributed to the formation of a new social reality. The contemporary world requires new ways of structuring intellectual, educational, and scientific landscapes. The concepts of cross-, inter-, poly-, trans-, post disciplinarity are increasingly used in the scientific community. Therefore, given the transformations taking place in science, it is too early to talk about the death of academic disciplines. In his work "Disciplines and the Future" A. Abbot concludes that "there is little new in interdisciplinary fermentation and that, in the absence of serious changes in the social structure of the university, it is unlikely that the disciplinary system will change significantly"1. On the other hand, even those researchers who belong to the same discipline do not always speak the same language and often are not aware of their terminological differences. Usually, language is the key barrier to interdisciplinary research. It requires scientists to think holistically, especially in the process of conceptualizing phenomena and objects of study.

The disciplinary division was one of the main features of the ancient system of knowledge. For example, mathematics was divided into arithmetic, geometry, and algebra. Plato's Academy can be considered the first higher educational institution of that time. Aristotle developed a system according to which the appropriate method had to be used to study a certain object. Later, this approach would become the basis for a disciplinary division of knowledge.

In the Middle Ages, monasteries became the centers of academic activity. Later first European universities were established. At this time, the seven liberal arts were clearly defined. They consisted of a quadrivium (music, arithmetic, geometry, and astronomy) and a trivium (grammar, rhetoric, and logic). J. Klein believes that it is in the late Middle Ages that we owe the emergence of discipline, as this term was first applied to three academic fields in which universities professionally trained, namely: theology, law, and medicine ${ }^{2}$.

During the Renaissance such disciplines as Greek literature, Hebrew, poetry, and history appeared. A separate niche in the educational process was occupied by the philosophy of Plato and Aristotle. At the same time, the separation and rapid development of natural science took place.

The disciplinary structure of knowledge was strengthened in the Enlightenment. The curriculum had expanded through medicine, economics, and agronomy. This process was accompanied by the emergence

\footnotetext{
${ }^{1}$ Abbott, A. (2002). The Disciplines and the Future. The Future of the City of Intellect. Stanford: Stanford University Press, 205.

${ }^{2}$ Klein, J. (1990). Interdisciplinarity: History, Theory and Practice. Detroit: Wayne State University Press, 20. 
of modern scientific specialties, as well as the belief of contemporary thinkers in the feasibility of classification and codification of knowledge into encyclopedic systems. The Enlightenment emphasized the progress of human knowledge through the power of reason and rationality. The basis of this approach was the formation of generally accepted procedures and methods within a particular discipline and greater specialization of knowledge, especially in science and mathematics ${ }^{1}$.

Another factor in the emergence of scientific disciplines was the gradual rejection of the idea that it is possible to know the world in its entirety. This was the case, for example, in ancient philosophy which had a holistic approach to understanding the reality. This became especially noticeable when the amount of knowledge about the surrounding world increased, which made it impossible to concentrate in "one hand". It became a norm for a scientist to engage in a highly specialized research. The decisive role in this process was played by the emergence of empiricism. It influenced the formation of a specific research methodology, when not ideas, conjectures, beliefs, dogmas, and traditions determined the truth or falsity of a statement, but sensory experience, physical parameters, and mathematical calculations. This process was especially noticeable during the scientific revolutions in the 16th - 18th centuries. It was in this period when fundamental sciences began to shape. Later, the specialization of knowledge was facilitated by the fact that there are educational institutions (including universities) and the profession of "scientist" was recognized. Research achievements in a particular field were legalized through the assignment of degrees and titles ${ }^{2}$.

There are several views on how the modern academic disciplines began. R. Neumann suggests that until the 19th century the development of disciplines took place outside universities, namely in academies, communities, specialized institutes (the Royal Society of London (1662), the French Académie Royale des Sciences (1666), while the the educational tradition of the Middle Ages still dominated in most universities. Among the important changes was the reorientation of universities to search activities. Research has ceased to be a rethinking of old ideas, and the practice of discovering new knowledge has emerged. Thus, since the 19th-century universities, their disciplinary structure, and their approaches to exploration have been reformed. Learning has shifted from interdisciplinary faculties to highly specialized knowledge ${ }^{3}$. D.Schumway and E.Messer-Davidov believed that modern disciplines arose with the division of the natural sciences into separate domains in the late 18th century, while "the humanities" is a 20th-century term used to name all branches of science that have been removed from the natural or social sciences ${ }^{4}$.

According to J. Klein, initially, disciplinary knowledge is formed as a reaction to external needs, and the specialization of knowledge in the 19th century was inter-scientific. The formation of the modern type of discipline is associated with the German educational reform by W. Humboldt in the 19th century, as well as the opening of the University of Berlin, which was the prototype of modern Western universities ${ }^{5}$. At this time a clear demarcation line was drawn between the "natural sciences" and the "humanities". Disciplines facilitated the selection and training of specialists the need for which has increased due to industrialization and advances in technology ${ }^{6}$. At the same time, disciplinary traditions were formed, i.e., scientists in a certain field were united not only by a common object of research but also by the requirements as to how exactly this research should be conducted. In the 20th century technical and computer sciences have gained unprecedented development.

To understand how the classification of scientific fields took place, it was necessary to determine the criteria of discipline. Scientific disciplines can be defined by their purpose, object, research methods, terminology, etc. Therefore, it is difficult to offer a definition that would cover the full range of its functioning. Although based on the etymology of the Latin words "disciplina" (teaching) and "discipulus" (student) there is a general understanding of why the concept of discipline has several meanings. According to M. Foucault, "discipline" can be used both in a general and in a specific context. He unequivocally states that discipline contributes to the creation of "discipline" in society ${ }^{7}$. The term that appears later, "academic (scientific) disciplines", is related to the primary meaning, but has a technical nature with a specific form

\footnotetext{
${ }^{1}$ Moran, J. (2002). Interdisciplinarity: The New Critical Idiom. London: Routledge, 5.

${ }^{2}$ Repko, A., Szostak, R., Buchberger, M. (2009). Introduction to Interdisciplinary Studies. SAGE Publications, 29-30.

${ }^{3}$ Neumann, R. (2009). Disciplinary. The Routledge International Handbook of Higher Education. London and New

York: Routledge, 489.

${ }^{4}$ Shumway, D., Messer-Davidow, E. (1991). Disciplinarity: An introduction. Poetics Today, 12 (2), 204.

${ }^{5}$ Klein, J. (1990). Interdisciplinarity: History, Theory and Practice. Detroit: Wayne State University Press, 20.

${ }^{6}$ Moran, J. (2002). Interdisciplinarity: The New Critical Idiom. London: Routledge, 13.

${ }^{7}$ Foucault, M. (1991). Discipline and Punish. The Birth of the Prison. London: Penguin, 352.
} 
of knowledge organization. Sometimes there is an identification of scientific disciplines with, for example, subjects areas taught in universities. However, not all scientific disciplines are represented in the curriculum and, conversely, not all subjects in the curriculum are necessarily separate academic disciplines.

In the 1960s the scientific community attempted to combine theoretical and empirical research into whether there are differences in scientific routine in different disciplines. Many potentially synonymous terms to the concept of discipline have emerged, i.e. "epistemic cultures"1, "community of practitioners"2, and "academic tribes" ${ }^{3}$. Later, metaphors are increasingly used to create a confrontation between disciplinary and interdisciplinary approaches to research. In particular, appealing to structural knowledge, such concepts as scientific boundaries, disciplinary territories, academic tribes, scientific federalism, knowledge migration, disciplinary bunker appear. The acquired knowledge began to be treated as a geographical area that can be fought for and controlled. However, there are subtle and clear differences in each of these terms. Over the next 20 years, research focused on the specifics of individual disciplines. In the 1980s, the first conceptual schemes and models of discipline as an object of holistic study were created. B. Agger later named such tendencies in science "disciplinary hegemony"4.

Another issue that emerged within the scientific community was the discussion about internal structure of a discipline and its criteria. According to L. Lattuka, the key components of the discipline are: subject (subject, principles, conclusions of research), linguistic (symbolic language that reflects the essence of the study), syntactic (development of the discipline based on a certain form of its organization), value (which object to study and how to do it) and communicative (interaction of disciplines with each other) ${ }^{5}$. At the same time, E. Buker points out that any discipline is determined by its history, vocabulary, key issues that lead research in the relevant direction, a set of methods and strategies, as well as a common epistemological understanding of phenomena ${ }^{6}$.

According to T. Kuhn, scientific disciplines are defined by models that outline the problem, methods that are involved in solving the problem, and the conclusions that researchers come to ${ }^{7}$. J. Klein emphasizes the ideological foundations of a particular discipline, research methods, and the criteria for assessing the reliability of the result ${ }^{8}$. M. Schommer-Aikins defines such criteria as the scope, methods of research and epistemological foundation ${ }^{9}$. According to A. Krishnan, a scientific discipline is characterized by the following factors: a specific object of study (although sometimes several disciplines can study a common object); accumulated disciplinary experience, (the result of the scientific research in particular field); hypotheses and theories aimed at streamlining this experience; special terminology and language of communication related to the object of study; a particular set of methods that meets the stated purpose of the study and the requirements of scientific work; institutionalization of the obtained results in the form of educational institutions, departments in universities, training courses, etc ${ }^{10}$.

Today there are hundreds of scientific disciplines. The number of disciplines not only increases but also the interaction between them changes. New forms of interdisciplinary communication are created based on joint projects and research methods. It is the increase in the number of disciplines and their diversity, the division into subdisciplines that made their integration possible. The combination of two distant areas of research is not that common. However, those disciplines that have communication bridges in the form

\footnotetext{
${ }^{1}$ Knorr-Cetina, K. (1999). Epistemic Cultures: How the Sciences Make Knowledge. Harvard University Press, 329.

${ }^{2}$ Lave, J., Wenger, E. (1991). Situated Learning: Legitimate Peripheral Participation. Cambridge University Press, Cambridge, 138.

${ }^{3}$ Becher, T., Trowler, P. (2001). Academic Tribes and Territories: Intellectual Enquiry and the Cultures of Disciplines. Milton Keynes: The Society for Research into Higher Education and Open University Press, 238.

${ }^{4}$ Agger, B. (1991). A Critical Theory of Public Life: Knowledge, Discourse and Politics in the Age of Decline. London: Falmer Press, 248.

${ }^{5}$ Lattuca, L. (2002). Learning Interdisciplinarity: Sociocultural Perspectives on Academic Work. Journal of Higher Education, 73, 715.

${ }^{6}$ Buker, E. (2003). Is Women's Studies a Disciplinary or an Interdisciplinary Field of Inquiry? Journal of the National Women's Studies Association, 15, 74-75.

${ }^{7}$ Kuhn, T. (1962). The Structure of Scientific Revolutions. Chicago: University of Chicago Press, 172.

${ }^{8}$ Klein, J. (1990). Interdisciplinarity: History, Theory and Practice. Detroit: Wayne State University Press, 336.

${ }^{9}$ Schommer-Aikins, M., Duell, O., Hutter, R. (2005). Epistemological Beliefs, Mathematical Problem-Solving Beliefs, and Academic Performance of Middle School Students. The Elementary School Journal, 105 (3), 289-304.

${ }^{10}$ Krishnan, A. (2009). What are Academic Disciplines? Some observations on the Disciplinarity vs Interdisciplinarity Debate. ESRC National Centre for Research Methods. NCRM Working Paper Series <http://eprints.ncrm.ac.uk/783/1/what_are_academic_disciplines.pdf> (2021, April, 08).
} 
of subdisciplines, neighboring disciplines, similar objects of study, common problems are more open to interdisciplinary researches.

Another debatable issue is whether it is possible to determine a specific moment of emergence of a particular discipline, as the initial for its scientific status, or as a turning point when its defining feature is formed. Historians of science have found a close connection between certain historical conditions and the development of disciplines. It points to the unpredictability and artificiality of modern disciplines and disciplinary boundaries. There was no obvious objective precondition for science to be systematized in such a list of disciplines. Sometimes there are "historic incidents" that can lead to the sudden creation of a new discipline. M. Dascal believes that there is no exact historic moment when a certain academic discipline is born $^{1}$. P.Bourdieu noted that "results that are specific to a particular area of research can be achieved only through personal relationships based on the coincidence of mutual meetings and acquaintances, as well as likes and dislikes inspired by common behavior"2.

Another component of the discussed issue is the difference between disciplines, i.e., disciplinary selfidentification. According to M. Daskal and K. Datz, the possibility "to call a field of research a discipline is important because the use of this term determines its position in the system of disciplines and provides such properties as a homogeneous field of study, a specific perspective, a set of methods or a sequence of theories"3.

The evolution of scientific disciplines has been influenced by many factors. Some of them managed to successfully exist and develop for a long time, while others either disappeared quickly (e.g., phrenology, ethnogenesis) or were forced to change under the social and political pressure (e.g., theology was transformed into religious studies) $)^{4}$. Socio-humanitarian areas of science are the most vulnerable to such changes, as they are often influenced by the historical and political context and can be used more as ideologies than as independent research programs. An example of this was the rise of anthropology during European colonization due to the great popularity of hypotheses about the advantages of developed cultures over primitive peoples, sorting by race, etc 5 .

Conclusion. Academic disciplines give knowledge a certain structure and create clear rules for the possibility of obtaining such knowledge. They indicate the objects we can study and how they relate to each other. They provide criteria to human knowledge and develop methods that govern our access to it.

The analysis of the history of discpilinarity shows how complex the scientific structure is. There are elements in which disciplinary science did not change much, e.g., each discipline has its research object and uses a particular set of methods. At the same time, most of existing academic disciplines are transforming due to the influence of technological factors, quick access to information, expansion of research tools, etc. We can clearly state that such evolution has had a significant impact on the organization of the work of a scientist. However, the question of what criteria knowledge must meet to be called a scientific discipline remains open. As more subject areas emerge, a scientific discipline is identified more by the methodology it applies to specific topics or research areas than by the topics or areas of research themselves ${ }^{6}$. There is also no clear prediction of possible changes in these criteria in 21 st-century science.

In general, the emergence of a new scientific discipline is always interdisciplinary. The need for a new scientific field points to several challenges: the inconsistency of new knowledge with the declared paradigm, the ineffectiveness of the existing methodology for new research, the lack of specialized language to identify new phenomena, objects, etc. These factors force scientists to turn to a wider discourse, to engage in external disciplinary approaches, to communicate with colleagues from other fields, to look for ways out of their research framework. There are no disciplines that do not change over time. New methods, approaches, and terms are integrated into a certain discipline, and thus, the problem of disciplinary demarcation becomes less relevant.

\footnotetext{
${ }^{1}$ Dascal, M., Dutz, K. (1996). The Beginnings of Scientific Semiotics. A Handbook of the Sign-Theoretic Foundations of Nature and Culture. De Gruyter, Berlin, Boston, 748.

${ }^{2}$ Bourdieu, P. (1988). Practical Reason: On the Theory of Action. Stanford University Press, Stanford, 2.

${ }^{3}$ Dascal, M., Dutz, K. (1996). The Beginnings of Scientific Semiotics. A Handbook of the Sign-Theoretic Foundations of Nature and Culture. Berlin, Boston: De Gruyter, 746.

${ }^{4}$ Krishnan, A. (2009). What are Academic Disciplines? Some observations on the Disciplinarity vs Interdisciplinarity Debate. ESRC National Centre for Research Methods. NCRM Working Paper Series

<http://eprints.ncrm.ac.uk/783/1/what_are_academic_disciplines.pdf> (2021, April, 08).

${ }^{5}$ Bainbridge, W. (2003). The Future in the Social Sciences. Futures 35, 639.

${ }^{6}$ Grieb, K. (1974). Area Studies and the Traditional Disciplines. The History Teacher 7 (2), 232.
} 


\section{References:}

1. Abbott, A. (2002). The Disciplines and the Future. In The Future of the City of Intellect. Stanford: Stanford University Press. [in English].

2. Agger, B. (1991). A Critical Theory of Public Life: Knowledge, Discourse and Politics in the Age of Decline. London: Falmer Press. [in English].

3. Bainbridge, W. (2003). The Future in the Social Sciences. Futures, 35, 633-650. [in English].

4. Becher, T., Trowler, P. (2001). Academic Tribes and Territories: Intellectual Enquiry and the Cultures of Disciplines. Milton Keynes: The Society for Research into Higher Education and Open University Press. [in English].

5. Bourdieu, P. (1988). Practical Reason: On the Theory of Action. Stanford: Stanford University Press. [in English].

6. Buker, E., (2003). Is Women's Studies a Disciplinary or an Interdisciplinary Field of Inquiry? Journal of the National Women's Studies Association, 15, 73-93. [in English].

7. Dascal, M., Dutz, K. (1996). The Beginnings of Scientific Semiotics. In A Handbook of the Sign-Theoretic Foundations of Nature and Culture. De Gruyter: Berlin, Boston. [in English].

8. Foucault, M. (1991). Discipline and Punish. In The Birth of the Prison. London: Penguin. [in English].

9. Grieb, K. (1974). Area Studies and the Traditional Disciplines. The History Teacher, 7 (2), 228-238. [in English].

10. Klein, J. T. (1990). Interdisciplinarity: History, Theory and Practice. Detroit: Wayne State University Press. [in English].

11. Knorr-Cetina, K. (1999). Epistemic Cultures: How the Sciences Make Knowledge. Harvard University Press. [in English].

12. Krishnan, A. (2009). What are Academic Disciplines? Some observations on the Disciplinarity vs Interdisciplinarity Debate. ESRC National Centre for Research Methods. NCRM Working Paper Series <http://eprints.ncrm.ac.uk/783/1/what_are_academic_disciplines.pdf> (2021, April, 08). [in English].

13. Kuhn, T. (1962). The Structure of Scientific Revolutions. Chicago: University of Chicago Press. [in English].

14. Lattuca, L. (2002). Learning Interdisciplinarity: Sociocultural Perspectives on Academic Work. The Journal of Higher Education, 73, 711-739. DOI: http://dx.doi.org/10.1353/jhe.2002.0054. [in English].

15. Lave, J., Wenger, E. (1991). Situated Learning: Legitimate Peripheral Participation. Cambridge: Cambridge University Press. [in English].

16. Moran, J. (2002). Interdisciplinarity: The New Critical Idiom. London: Routledge. [in English].

17. Neumann, R. (2009). Disciplinary. In The Routledge International Handbook of Higher Education. London and New York: Routledge. [in English].

18. Repko, A., Szostak, R., Buchberger, M. (2009). Introduction to Interdisciplinary Studies. SAGE Publications. [in English].

19. Schommer-Aikins, M., Duell, O., Hutter, R. (2005). Epistemological Beliefs, Mathematical Problem-Solving Beliefs, and Academic Performance of Middle School Students. The Elementary School Journal, 105 (3), 289-304. [in English].

20. Shumway, D., Messer-Davidow, E. (1991). Disciplinarity: An Introduction. Poetics Today, 12 (2), 201-225. [in English]. 